\title{
Birth weight and gestational age among children of Danish pharmacy assistants
}

\author{
Inger Schaumburg, Jørn Olsen
}

\begin{abstract}
Study objective-The aim was to investigate whether specific types of work or exposures among pharmacy assistants were correlated with changes in birth weight or gestational age.

Design-The study was a nationwide historical cohort with open entry of all female members of the union of pharmacy assistants during 1979 to 1984 .

Participants-The cohort comprised 4939 pharmacy assistants under $\mathbf{4 0}$ years of age. The questionnaire was answered by $93 \%$.

Measurements and main resultsInformation on birth weight and gestational age was obtained by linkage to the national birth register. Exposure information on type of work and exposure to pharmaceutical and chemical products during pregnancy was self reported. Only small and non-significant differences in birth weight and gestational age were found between the compared groups. Mean birth weight was $50 \mathrm{~g}$ above the national mean and gestational age was longer $(p<0.0005)$.

Conclusions-Compared to the Danish population, children of pharmacy assistants are at low risk for experiencing low birth weight and preterm birth. Social status and less smoking during pregnancy among pharmacy assistants might explain the slightly greater mean birthweight and gestational age in this sector of the population.
\end{abstract}

Birth weight is an important predictor of perinatal mortality and childhood growth and development. In some countries birth weight is noted with reasonable precision and is available from birth registers. Fetal growth, and thus birth weight, is to some extent determined by environmental factors, although genetic and hormonal factors are of greater importance. Birth weight is known to vary with race, maternal height, educational level, previous miscarriage, premature birth, age, and parity. ${ }^{1-3}$

Among environmental factors, although maternal smoking has been shown consistently to reduce birth weight in a dose-response fashion, ${ }^{2-5}$ and heavy alcohol consumption during pregnancy lowers birth weight, ${ }^{67}$ information about the effect of occupational exposures is sparse.

The analyses presented here are part of a larger study covering several types of reproductive failures among Danish pharmacy assistants. Previously, women working in the pharmaceutical industry or at pharmacies have been reported to experience an increased risk of infertility, ${ }^{8}$ prolonged time to pregnancy, ${ }^{9}$ spontaneous abortions, ${ }^{10-12}$ and congenital malformations among their offspring. ${ }^{11}$ This study is explorative and descriptive and the aim was to investigate whether specific types of work task or exposures among pharmacy assistants were correlated with birth weight or gestational length. More information on the study has been published. ${ }^{910}$

\section{Methods}

The study is a nationwide historical cohort study with open entry consisting of all female members of the national union of the pharmacy assistants. The study group consists of all gainfully employed members of the union during January 1 st 1979 to December 31st 1984, less than 40 years of age on December 31st, 1978. Data on type of pharmacy, occupation, and exposure to drugs and chemicals are self reported. The questionnaire was mailed to 4939 pharmacy asistants in 1985 and 4585 responded $(93 \%)$.

Data on birth weight and gestational length were obtained by linkage to the national register on birth certificates (The Danish Medical Birth Register) by means of the personal identity number. Data on births are considered complete as there is complete clearing between the Medical Birth Register and the civil registration system. ${ }^{13}{ }^{14}$ However, four percent of the births found in the register were not reported in the questionnaires by the participating women.

Birth weight was measured at the time of delivery by the midwife and noted in $10 \mathrm{~g}$ intervals. Gestational age was measured in full weeks from the first day of last menstruation period, and was usually corrected by ultrasound scanning when dates were uncertain. Even so, gestational age was recorded as uncertain in five percent.

Low birth weight is defined as birth weight less than $2500 \mathrm{~g}$ and early birth as births before 38 full weeks of gestation (the WHO definition of preterm birth, less than 37 weeks of gestation, was not used for numerical reasons)

Only women who worked during pregnancy for more than one week $(94 \%$ of all) are included in the analyses (1882 single births). The unit of analysis in the present context is a birth (not the woman) and the majority of women $\left(78^{\circ}{ }_{0}\right)$ only had one birth during the study period (average 1.3 births per woman).

Analysis of variance (ANOvA) ${ }^{15}$ was used, together with the unconditionally logistic regression model. Mother's age, parity, smoking, and alcohol consumption were considered as 
Table I Basic characteristics of the study base

\begin{tabular}{lcc}
\hline & No of births & $\%$ \\
\hline Age (years) & & \\
$15-24$ & 373 & 20 \\
$25-34$ & 1463 & 78 \\
$35-45$ & 46 & 2 \\
Parity & & \\
0 & 936 & 50 \\
1 & 800 & 43 \\
$2+$ & 146 & 8 \\
Smoking (cigarettes per day) & & \\
$\quad$ Non-smokers & 1255 & 67 \\
$1-9$ & 293 & 16 \\
$10-14$ & 226 & 12 \\
$15-$ & 108 & 6 \\
Alcohol (drinks per week) & & \\
0 & 616 & 33 \\
$1-4$ & 1142 & 61 \\
$5-9$ & 79 & 4 \\
$10-$ & 5 & 0 \\
No information & 40 & 2 \\
All & 1882 & \\
\hline
\end{tabular}

possible confounding variables (table I). All indicated confidence limits are $95 \%$ limits.

\section{Results}

BIRTH WEIGHT

The mean birth weight among the pharmacy assistants was $3450 \mathrm{~g}$ compared with the Danish population mean of $3400 \mathrm{~g}$. Low birth weight was found among $3.1 \%$ and preterm birth (before 37th week of gestation) among 3.0\% of pharmacy assistants compared to $5.0 \%$ and $4.5 \%$ mean according to type of variance adjusted for
Table II Birth weight: deviations from grand work. Analysis of mother's age and smoking habits (model 1) and additionally gestational age (model 2)

\begin{tabular}{|c|c|c|}
\hline & \multicolumn{2}{|c|}{ Deviations from grand mear } \\
\hline & Model 1 & Model 2 \\
\hline $\begin{array}{l}\text { Type of pharmacy } \\
\text { Rural pharmacy } \\
\text { Urban pharmacy }\end{array}$ & $\begin{array}{r}+13 \cdot 7 \\
-9 \cdot 1\end{array}$ & $\begin{array}{r}+17 \cdot 3 \\
-9.9\end{array}$ \\
\hline $\begin{array}{l}\text { Hospital-, production pharmacy } \\
\text { and pharmaceutical industry }\end{array}$ & $\begin{array}{l}\mathrm{y} \\
+37 \cdot 2 \\
+3.0\end{array}$ & $\begin{array}{l}-25 \cdot 3 \\
-11.4\end{array}$ \\
\hline $\begin{array}{l}\text { Other type of workplace } \\
\text { Grand mean (grams) } \\
\text { p value (main effect) }\end{array}$ & $\begin{array}{c}-35 \cdot 0 \\
3488 \\
0.65\end{array}$ & $\begin{array}{c}-11.4 \\
3450 \\
0.68\end{array}$ \\
\hline \multicolumn{3}{|l|}{ Type of work } \\
\hline $\begin{array}{l}\text { Reference work } \\
\text { Production }\end{array}$ & $\begin{array}{l}-1 \cdot 2 \\
+2 \cdot 9\end{array}$ & $\begin{array}{l}-7 \cdot 2 \\
+29 \cdot 4\end{array}$ \\
\hline Dispensary & $\begin{array}{l}+9.3 \\
-9\end{array}$ & $-7 \cdot 7$ \\
\hline Identification & $-45 \cdot 3$ & $-24 \cdot 7$ \\
\hline $\begin{array}{l}\text { Other } \\
\text { - }\end{array}$ & $-46 \cdot 3$ & $-22 \cdot 0$ \\
\hline $\begin{array}{l}\text { Grand mean (grams) } \\
\text { p value (main effect) }\end{array}$ & $\begin{array}{l}3448 \\
0.91\end{array}$ & $\begin{array}{l}3450 \\
0 \cdot 70\end{array}$ \\
\hline
\end{tabular}

Table III Birth weight according to self reported exposure during pregnancy (daily or weekly exposure). Analysis of variance

\begin{tabular}{|c|c|c|c|c|c|}
\hline Exposure & $\begin{array}{l}\text { No of } \\
\text { births }\end{array}$ & $\begin{array}{l}\text { Mean } \\
b w\end{array}$ & $\begin{array}{l}95 \% C I \\
+1-\end{array}$ & $\begin{array}{l}\text { Deviation from } \\
\text { ref means }\end{array}$ & $\begin{array}{l}P \text { value } \\
\text { (main effect) }\end{array}$ \\
\hline Reference & 709 & 3470 & 39 & - & - \\
\hline Antibiotics & 538 & 3440 & 43 & -9 & $0 \cdot 60$ \\
\hline Heart medicines & 40 & 3560 & 136 & 111 & $0 \cdot 16$ \\
\hline Cancer drugs & 8 & 3280 & 302 & -216 & $0 \cdot 24$ \\
\hline Anticoagulants & 18 & 3520 & 214 & 37 & $0 \cdot 76$ \\
\hline Sex hormones & 37 & 3610 & 163 & 142 & 0.09 \\
\hline Other hormones & 112 & 3460 & 87 & 2 & 0.96 \\
\hline Antidiabetics & 20 & 3440 & 246 & 2 & 0.99 \\
\hline Psychopharmaceuticals & 58 & 3510 & 126 & 57 & 0.39 \\
\hline Pain killers & 254 & 3490 & 60 & 25 & 0.37 \\
\hline Antiepileptics & 110 & 3520 & 92 & 56 & $0 \cdot 30$ \\
\hline Antirheumatics & 43 & 3420 & 151 & -42 & 0.59 \\
\hline Solvents & 264 & 3490 & 65 & 20 & 0.47 \\
\hline Pesticides & 61 & 3520 & 110 & 25 & $0 \cdot 70$ \\
\hline Heavy metals & 48 & 3580 & 135 & 91 & $0 \cdot 21$ \\
\hline Preservatives & 354 & 3440 & 53 & -11 & 0.63 \\
\hline All & 1882 & & & & \\
\hline
\end{tabular}

respectively among singleton births in Denmark in $1981 .{ }^{14}$ The sex ratio was comparable with the national figures.

Birth weight according to type of pharmacy and occupation did not differ among the compared groups. The analysis of variance as seen in table II only showed small and non-significant differences before or after adjustment for mother's age and smoking habits. Additional adjustment for gestational age did not alter these findings. Birth weight according to self reported exposure is shown in table III. The analysis of variance was performed adjusted for age, parity, smoking, and alcohol consumption. Women exposed to cytostatics daily or weekly had an average birth weight that was $200 \mathrm{~g}$ lower than the overall average. Average birth weight was $100 \mathrm{~g}$ lower among women exposed to cytostatics monthly. However, none of the differences were statistically significant.

The frequency of low birth weight did not differ significantly according to type of pharmacy, occupation, or exposure to drugs or chemicals (not shown). Women working with bottling of pharmaceuticals and women with "other types of jobs" showed an increased but statistically nonsignificant odds ratio for low birth weight.

\section{GESTATIONAL AGE}

Birth before 38 weeks of gestation was analysed according to type of work. Women working on the identification of pharmaceuticals had an increased odds ratio for early birth, but it was not statistically significant.

Logistic regression analyses were performed using birth before 38 weeks of gestation as the outcome variable and exposure to a number of different products or chemicals as predictors (table IV). Among eight women who recorded daily or weekly exposure to cytostatics during pregnancy, two gave birth before the 38th week of gestation (35th and 36th week respectively). However, this excess was not statistically significant as indicated by the wide confidence limit $(95 \% \mathrm{CI}=0 \cdot 9-31 \cdot 6)$. Length of pregnancy was very close to 40 weeks on average for all pharmacy assistants ( $39 \cdot 8$ weeks). No differences were found according to type of pharmacy or occupation (data not shown).

\section{Discussion}

Comparing birth weight and gestational length among groups of pharmacy assistants according to type of work or exposure did not reveal major differences which might indicate occupational hazards. It seems unlikely that a large number of pharmacy assistants were exposed to chemical agents in doses which have a major impact on fetal growth or on duration of gestation. However, a number of limitations of the study should be considered. Working conditions among pharmacy assistants may be too similar to allow identification of any single risk group; or exposure data may be too crude and imprecise. The relatively small number of women in the study yielded rather limited scientific information for some of the specific work tasks or exposures, as indicated by the broad confidence limits. 
Table IV Early birth according to self reported exposure during pregnancy (daily or weekly). Logistic regression analysis adjusted for mother's age, parity, and alcoholl tobacco consumption. Where data are too few, unadjusted odds ratios (OR) are given

\begin{tabular}{|c|c|c|c|c|}
\hline & $\begin{array}{l}\text { No of } \\
\text { births }\end{array}$ & $\begin{array}{l}\text { No of } \\
\text { early births }\end{array}$ & $\begin{array}{l}\text { OR } \\
\text { unadjusted }\end{array}$ & $\begin{array}{l}95^{\circ} \text { o confidence } \\
\text { limits }\end{array}$ \\
\hline Reference & 714 & 35 & $1 \cdot 0$ & - \\
\hline Antibiotics & 542 & 23 & 0.67 * & $0.41-1 \cdot 12$ \\
\hline Heart medicines & 40 & 2 & $1 \cdot 02$ & $0.2-3.8$ \\
\hline Cancer drugs & 8 & 2 & $6 \cdot 50$ & $0.9-31 \cdot 6$ \\
\hline Anticoagulants & 18 & 2 & $2 \cdot 43$ & $0 \cdot 4-9 \cdot 7$ \\
\hline Sex hormones & 37 & 3 & $1 \cdot 72$ & $0.4-5 \cdot 3$ \\
\hline Other hormones & 112 & 6 & 1.09 & $0.4-2 \cdot 6$ \\
\hline Antidiabetics & 20 & 3 & $3 \cdot 40$ & $0.8-11 \cdot 3$ \\
\hline Psychopharmaceuticals & 58 & 4 & 1.44 & $0.4-3.9$ \\
\hline Pain killers & 255 & 8 & 0.63 & $0 \cdot 3-1 \cdot 3$ \\
\hline Antiepileptics & 110 & 5 & 0.92 & $0 \cdot 3-2 \cdot 3$ \\
\hline Antirheumatics & 43 & 3 & 1.46 & $0.3-4.5$ \\
\hline Solvents & 268 & 10 & $0 \cdot 58^{\star}$ & $0 \cdot 29-1 \cdot 19$ \\
\hline Pesticides & 62 & 2 & 0.65 & $0 \cdot 0-2 \cdot 4$ \\
\hline Heavy metals & 48 & 2 & 0.84 & $0 \cdot 0-3 \cdot 1$ \\
\hline Preservatives & 357 & 17 & $0 \cdot 78^{\star}$ & $0.44-1.37$ \\
\hline All & 1882 & 99 & & \\
\hline
\end{tabular}

* Logistic regression controlled for the same variables as in table III

Controlling for confounding is only partly possible since the majority of causes of growth retardation and preterm birth are unknown. Age, parity, social characteristics, smoking, and drinking habits are known to influence these pregnancy outcomes. ${ }^{1-7}$

Mean birth weight among children of pharmacy assistants was $50 \mathrm{~g}$ higher than the average Danish birth weight, and the proportions of newborns with low birth weight and preterm birth were lower. This is probably due to the relatively high social standard and less frequent smoking among pharmacy assistants. In this study $35^{\circ}{ }_{0}$ of the women smoked during pregnancy compared to $39^{\circ}{ }_{0}$ in a sample of Danish Women. ${ }^{16}$ Gestational age among children of pharmacy assistants was longer compared with gestational age for all children born in Denmark during the years 1979 to 1983 $\left(\chi^{2}=25.95, \mathrm{p}<0.0005, \mathrm{df}=6\right) .{ }^{17}$ The difference in mean birth weight may be explained by the increased duration of pregnancies among pharmacy assistants.

In the statistical analysis pregnancies are treated as independent events, and repeated pregnancies in the study period among the participating women are not taken into consideration in the analysis. However, most women contributed only one birth (on average 1.3) and the impact of this problem on the estimates is considered to be minor. ${ }^{18}$

Unfortunately, the study provided little information on pharmacy assistants exposed to cytostatics. However, some cytostatics have been shown to be teratogenic in animal studies and in women who have taken cytostatic drugs during pregnancy. ${ }^{19}$ Additionally, exposure to cytostatic drugs among nurses has been reported to increase the risk of spontaneous abortion ${ }^{20}$ and congenital malformation in the offspring. ${ }^{21}$

This paper was made possible by the efficient cooperation of the Association of Danish Pharmacy Technicians. The study was supported by a grant from the Danish Work Environment Fund (1984/14) and the Danish Medical Research Council (12-5075).

1 Thomson AM. Fetal growth and size at birth. In: Baron SL, Thomson AM, eds. Obstetrical epidemiology. London Academic Press, 1983: 89-142.

2 Kleinmann JC, Madan S. The effects of maternal smoking, physical stature and educational attainment on the incidence of low birth weight. $A m \mathcal{F}$ Epidemiol 1985; 121 843-55.

3 Kramer MS. Intrauterine growth and gestational duration determinants. Pediatrics 1987; 80: 502-11

4 Rantakallio P, Hartikainen-Sorri AL. The relationship between birth weight, smoking during pregnancy and maternal weight gain. Am f Epidemiol 1981; 113: 590-5.

5 Naeye RL. Effects of maternal cigarette smoking on the fetus and placenta. Br $\mathcal{F}$ Obstet Gynaecol 1978; 85: 732-7.

6 Kaminski M, Rumeau C, Schwarts D. Alcohol consumption in pregnant women and the outcome of pregnancy. Alcoholism Clin Exper Res 1978; 2: 155-63.

7 Olsen J, Rachootin P, Schiødt AV. Alcohol use, conception time and birth weight. $\mathcal{F}$ Epidemiol Community Health 1983; 37: 63-5.

8 Rachootin P, Olsen J. The risk of infertility and delayed conception associated with exposures in the Danish conception associated with exposures in
workplace. 7 Occup Med 1983; 25: 394-402.

9 Schaumburg I, Olsen J. Time to pregnancy among Danish pharmacy assistants. Scand $\mathcal{F}$ Work Environ Health 1989; 15: 222-6.

10 Schaumburg I, Olsen J. The risk of spontaneous abortion among Danish pharmacy assistants. Scand $\mathcal{f}$ Work Environ Health 1990; 16: 169-74

11 Hansson E, Jansa S, Wande $H$, Källén B, Östlund E. Pregnancy outcome for women working in laboratories in some of the pharmaceutical industries in Sweden. Scand $\mathcal{F}$ Work Environ Health 1980; 6: 131-4.

12 Taskinen $\mathrm{H}$, Lindbohm ML, Hemminki K. Spontaneous abortions among women working in the pharmaceutical industry. Br F Indust Med 1986; 43: 199-205.

13 Knudsen LB, Kristensen FB. Monitoring perinatal mortality and perinatal care with a national register: conten and usage of the Danish medical birth register. Community Med 1986; 8: 29-36.

14 Medicinsk fødselsstatistik 1981 (Medical Birth Statistics). Vitalstatistik 1: 13. Copenhagen: Sundhedsstyrelsen, 1985.

15 SPSS/PC +: Analysis of variance: ANOVA. Chicago: SPSS Inc, 1988.

16 Olsen J, Frische G, Kirchheiner H. Smoking habits of pregnant women (in Danish). Ugeskr Lager 1986; 148:

17 Juul S, Olsen J, Knudsen LB. Regional distribution of birth weights in Denmark during the period 1979-1983 (in Danish). Ugeskr Lager 1989; 151: 885-9.

18 Butler WJ, Kalasinski LA. Statistical analysis of epidemiologic data of pregnancy outcomes. Environ Health Perspect 1989; 79: 223-7.

19 Schardein JL. Chemically induced birth defects. New York Marcel Dekker, 1985: 880.

20 Selevan SG, Lindbohm ML, Hornung RW, Hemminki K. A study of occupational exposure to antineoplastic drug and fetal loss in nurses. N Engl f Med 1985; 313: 1173-8.

21 Hemminki K, Kyyrönen P. Lindbohm ML. Spontaneous abortions and malformations in the offspring of nurses exposed to anaesthetic gases, cytostatic drugs, and other potential hazards in hospitals, based on registered information of outcome. $\mathcal{F}$ Epidemiol Community Health 1985; 39: $141-7$. 